I have a vivid recollection of one of my teachers whose habit was as I was about to divide the second cranial nerve in an enucleation to say, "it was the right eye, wasn't it, Payne?" One knew very well that he would say this, but it never failed to send a shiver down the spine, and I have always felt compelled to verify the laterality by all possible means in the theatre immediately before operations of this sort.-I am, etc.,

Plymouth

I. W. Payne.

\section{Staffing of Casualty Departments}

SIR,--The recent crisis in the staffing of casualty departments throughout the country makes one look at the future-and at the past. The explanation given that the number of overseas graduates, who usually staff these departments, is drastically falling, produces a situation which is unlikely to improve. In the "good" (or "bad") old davs there were no overseas graduates. Casualtv departments in small hospitals were staffed by a competent sister, who would call on the house-surgeon when she was in trouble. Since the advent of the N.H.S., however, it seems to have become legally essential that every case attending hospital must first be seen by a "qualified" doctor. This doctor, for the sake of argument, may be totally inexperienced, come from some remote foreign medical school whose training is quite different from ours, have only spent a minimal time in Britain, and may only speak a smattering of English. This, however, is medicolegally more acceptable than that the patient be seen by a fully competent sister with many years of casualty experience in this country behind hersurely an absurd state of affairs?

We are constantly giving lip service to improvement of the status of the nursing profession. We change their names, we change their uniforms, we change their pay, but as soon as it comes to giving them clinical responsibility-surely the acid test of our opinion of their worth-we hold up our hands in horror.

A lamentable situation has arisen in which many casualty departments throughout the country are being closed at evenings and weekends. Surely the time has come when the Department of Health, the regional boards. and perhaps the judiciary, should reconsider as a matter of urgency the whole question of whether or not casualty departments mav remain open even though there is no medical officer immediately available. Are we to deny the public a service which could so easily be given just because of the constant fear of possible litigation?-I am, etc.,

\section{Ashford Hospital,
Ashford, Middx.}

\section{ROBIN BURKITT.}

\section{Benzene Hexachloride Poisoning}

SIR,-I am writing to record a case of nearly fatal poisoning in an 8-year-old boy resulting from ingestion of biscuits found on a rubbish tip. This had been sprayed on the previous night with Cooper's Tip Dressing, which contains $4 \%$ benzene hexachloride of which only $0.5 \%$ was of the gamma isomer.
The patient was brought home from school at 3 p.m. on 4 June vomiting and drowsy. He complained that he felt unwell, and after further vomiting fell into a restless torpor. At the time of admission to hospital at $9.30 \mathrm{p} . \mathrm{m}$. he was in a stuporous state, but passing urine, vomiting, and protesting on examination. He had a suggestion of neck stiffness; pupils were dilated and sluggish in their reaction to light, and his fundi were thought to be normal. Tendon reflexes were reduced and difficult to elicit; plantar responses were flexor and abdominal reflexes absent. He had a bradycardia of 52 per minute with some sinus arrhythmia. The clinical diagnosis of presumed poisoning was made, and he was treated by aspiration of the stomach contents and put on half-hourly observation throughout the night.

By morning he had begun to twitch and his general state of conciousness had lapsed so that he no longer responded to painful stimuli and his pupils were quite fixed, dilated, and diverging. An intravenous infusion of $500 \mathrm{ml}$. of $10 \%$ mannitol was established to combat presumed cerebral oedema. We now learned that at noon on the day of admission he had eaten chocolate biscuits taken from a rubbish tip, which had been sprayed with Cooper's Tip Dressing Powder on the previous evening. He had taken about a dozen biscuits, and the wrappings proved to contain benzene hexachloride, which is present in $4 \%$ concentration in the tip dressing powder

Investigations carried out included examination of his urine on admission for presence of sugar, salicylates, and phenothiazines which gave negative results: blood sugar $131 \mathrm{mg} . / 100 \mathrm{ml}$; pseudocholinesterase levels were at the low:r range of normal, being 37 Rappaport units/ml. on admission and 41 Rappaport units $/ \mathrm{ml}$. 12 hours after admission. His serum electrolytes showed some salt depletion with a sodium level of 111 $\mathrm{mEq} / 1$., chloride $88 \mathrm{mEq} / 1$, blood urea 20 $\mathrm{mg} . / 100 \mathrm{ml}$.

After the infusion of mannitol his level of consiousness improved so that he responded to painful stimuli. Grand mal convulsions supervened and he was given $5 \mathrm{ml}$. paraldehyde intramuscularly and intravenous dexamethasone. The boy's condition remained critical until 48 hours after admission, but by 72 hours he seemed to have made a full recovery.

Though benzene hexachloride was not identified in the vomitus, the circumstantial evidence for this being the cause of his illness is strong. Kay and Kuder ${ }^{1}$ have described eight cases of poisoning following the ingestion of food containing $4 \%$ benzene hexachloride, three of whom died within seven hours of consuming the food, after having convulsions, coma, and pulmonary oedema. (Vomiting was thought to have prevented serious illness in others). Necropsy additionally showed cerebral congestion and oedema and renal ischaemia with haemorrhage.

Benzene hexachloride has nine stereoisomers, of which gammahexane is the least toxic to humans and the most effective insecticide. ${ }^{2}$ Even with the gamma isomer fatalities have been reported by Attygalle and Fernando, ${ }^{3}$ where the undiluted insecticide was drunk in mistake for alcohol.

I feel that this case merits publicity to prevent recurrences elsewhere.-I am, etc.,

\section{B. G. P. Macnamara.}

George Eliot Hospital,

Nuneaton.

REFERENCES

Kay, R. W. W., Kuder, G. G.. Sessler, W. A., 3, 72 . Martindale, Extra Pharmacopoeia, ed. R. G. Todd
25th edn., p. 525, 528. London, Pharmaceutical Press, 1967.

Attygalle, D. J., and Fernando, W. D. L., Ceylon
Medical Fournal, 1959, 5, 64.

\section{Treatment of Typhoid}

SIR,-The three recent papers and your leading article (8 August, pp. 318, 320, 323, and 297 respectively) on the treatment of enteric fever with trimethoprimsulphamethoxazole prompt us to record a proved relapse of Salmonella paratyphi B infection following such treatment.

A man aged 29 developed fever on 26 February 1969, after a holiday in the Canary Islands. Five days later he was admitted to hospital and the suspected diagnosis of enteric fever was established by isolation of $S$. paratyphi $B$ from blood cultures. Treatment with trimethoprim-sulphamethoxazole-two tablets six hourlywas started one week after the onset of his illness. His fever subsided over the next six days. Treatment was continued for a total of two weeks. No ill effects of this large dose were noted. Before discharge seven negative stools and six negative urine cultures were obtained.

Six weeks after the onset of the initial illness, and three weeks after the end of treatment, he was readmitted with a recurrence of fever of three days' duration. Blood and stool cultures again grew $S$. paratyphi $B$. The relapse was treated by chloramphenicol and his recovery was uneventful.

Two other patients with enteric fever, one caused by $S$. typhi and the other by $S$. paratyphi $B$, were treated similarly during the summer of 1969 and neither relapsed. Relapse is an important complication of enteric fever, and any treatment which could be shewn significantly to reduce the incidence of relapse would be of great value. Relapse rates should therefore be recorded carefully in trials of the treatment of enteric fever, and we look forward with interest to Dr. S. A. Kamat's next report, which will include these important data for his large series. We have not come across another report of relapse following this treatment.We are, etc.

\section{H. P. LAMBERT.}

\section{St. George's Hospital,
London S.W.17.}

J. D. Frengley.

\section{Folate and Vitamin $B_{12}$ in Epilepsy}

SIR,-I was interested to read your leading article on "Folate and Vitamin $B_{12}$ in Epilepsy" (27 June, p. 774). In subsequent correspondence Dr. N. S. Gordon (25 July, p. 226) has drawn attention to the association of reduced serum folate with the gradual mental deterioration observed in some children during the prolonged administration of anticonvulsant drugs.

The majority of studies have confirmed the threefold concentration of folate in the spinal fluid compared with serum, and this ratio has been shown to be maintained in treated epileptic patients in the presence of reduced serum folate concentrations. Whether these reduced levels of serum and C.S.F. folate reflect alterations in cerebral folate activity, as suggested by some reports describing the neurological and psychiatric complications of folate deficiency, is important but difficult to define in man.

Recent studies in rats, ${ }^{1}$ gerbils, ${ }^{2}$ and cats ${ }^{3}$ have indicated that brain tissue is capable of maintaining a normal level of folate activity, principally in the form of 5 methyltetrahydrofolate, in the presence of diphenylhydan- 
toin (D.P.H.) and of reduced levels of serum and C.S.F. folate. In weanling rats placed on a folate-deficient diet profound falls of serum and tissue folate were observed, in contrast to cerebral folate concentrations which were maintained within the normal range. A similar reduction in serum and tissue folate concentrations was demonstrated in rats administered toxic doses of D.P.H. daily for up to 120 days together with a folate deficient diet; in the presence of substantial serum and tissue concentrations of D.P.H., no significan change in cerebral folate levels was observed. Tissue folate and D.P.H. concentration were determined in cats rendered ataxic by the daily oral administration of D.P.H. for one to four weeks. In the presence of moderate depression of the serum, tissue, and C.S.F. folate concentrations, only mino changes were demonstrated in regional cerebral folate activity. Cats receiving D.P.H together with folic acid supplements also exhibited ataxia in the presence of substantial increases in serum tissue and C.S.F. folate and a minor increase in cerebral folate concentration.

These findings indicate that D.P.H.induced ataxia in cats and the prolonged administration of D.P.H. to rats are not associated with significant alterations of cerebral folate concentration. The ability of D.P.H. to raise, with low toxicity, the convulsant threshold for electrical stimuli in cats led to its successful introduction in the management of epilepsy 30 years ago. ${ }^{4}$ Although the anticonvulsant action of D.P.H. was not investigated in the studies described, the maintenance of normal cerebral folate activity in the presence of D.P.H suggests that this therapeutic action is not mediated through change in cerebral folate concentration.

D.P.H.-induced folate deficiency appears to be a complication unrelated to any therapeutic benefit. Whether the insidious neuropathy, unresponsive to folic acid supplements, ${ }^{5}$ and mental deterioration observed in some epileptic subjects are related to an ultimate reduction in cerebral folate activity or to a direct neurotoxic action of D.P.H. on neural tissue has still to be defined. The unique case of folic acid deficiency from malabsorption with mental retardation, epilepsy, and basal ganglia calcification reported by Lanzkowsky et al, has confirmed the importance of cerebral transport mechanisms in the maintenance of cerebral folate activity in man.-I am, etc.,

$$
\begin{aligned}
& \text { Royal United Hospital, } \\
& \text { Bath. }
\end{aligned}
$$

\section{D. Allen.}

\section{REFERENCES}

1 Allen, C. D, and Klipstein, F. A., Neurolory (Minneapolis) $1970,20,403$

2 Allen, C. D., and Goldblatt, D., 1970, unpublished. 3 Allen, C. D., and Klipstein, F. A.. Transaction of the American Neurological Association, in

press.
Putnam, T. J., and Merritt, H. H., Science, 1937, 85. 525.

Horowitz, S. J., Klipstein, F. A., and Lovelace,
R. E., Lancet, 1968 , 563 .

Lanzkowskv, P., Erlandson, M. E., and Bezan,
A. I., Blood, 1969, 34, 452.

\section{Skin Disease and the Gut}

SIR,-I read with interest your leading article on the above subject (1 August, p. 240). On going to Singapore where tropical sprue occurs with some frequency in the
European population ${ }^{1}$ I carried out a survey of skin diseases occurring for the first time since arrival in the tropics to see whether intestinal malabsorption, which is a cardinal feature of sprue, was associated with any one skin disease. Various abnormalities of the skin have been described in association with tropical sprue and idiopathic steatorrhoea which include pigmentation ${ }^{2}$ and psoriasiform eruptions. ${ }^{3}$

In my survey I found one group of 35 patients, mostly women, presenting with a patchy eczematous dermatitis of hands and feet, in 17 of whom there was evidence from absorption studies and jejunal biopsy of an enteropathy consistent with early tropical sprue. The enteropathy and the skin disease responded to therapy with folic acid and broad spectrum antibiotics normally given for tropical sprue.

I was also able to substantiate the findings of England and O'Brien ${ }^{4}$ that apparently normal Europeans in Singapore had normal mucosae, also that there was no enteropathy associated with tropical impetigo, prickly heat, and acne in the tropics. ${ }^{5}$ I am, etc.,

\section{Dermatology Department,
British Military Hospital, Munster. B.F.P.O. 17}

\section{REFERENCES}

O'Brien, W., and England, N. W. J., British Medical fournal, 1966, 2, 115

Manson-Bahr. P, and Willoughby, H., Quarterly 7ournal of Medicine, 1930, 23, 411

Cooke, W. T., Peeney, A. L. P. and Hawkins, 5 9.

Fryland. N. W. J., and O'Brien, W., Gut, 1966 7. 128

Hindson, T. C., Archives of Dermatology (in press)

\section{George III and the Mad-business}

SIR,-Dr. M. M. Salzmann (15 August, p 406) questions the recent opinions that George III's "insanity" was due to porphyria rather than being idiopathic. This is an interesting academic argument that, no doubt, experts will continue to pursue.

However, Dr. Salzmann, quite unwittingly, does raise a completely different issue. Believing that King George's insanity was idiopathic, the writer apologizes for his beliefs by writing "without wishing to recast any slur on our monarchy's ancestors" (my italics). I feel that a strong undercurrent of this sentiment lies behind much of the recent interest in George III's illness. In other words, if the illness was due to porphyria then the Monarch was an unfortunate man suffering from organic disease, albeit not recognized at the time. On the other hand, if the illness cannot be identified with a biochemical abnormality, then in some way King George III was deserving of censure and stigmatized on that account

What a lot of nonsense this is. Who knows that medical science will not at some future time find a structural or biochemical basis for all mental illness? The situation is especially ironic because the national indignation aroused by the treatment meted out to George III led to the appointment by the House of Lords of a committee of inquiry. Recommendations resulted in humane reforms in the treatment of mental illnesses, but old attitudes die hard. I raise this point because $I$ assume that the writer of the letter is a psychiatrist. As long as psychiatrists are prepared to perpetuate this irrational prejudice then the longer will their specialty be a cinderella in the N.H.S.- am, etc.,

Philip Jacobs.

Solihull,

\section{Sleeping Pills}

SIR,-You end your leading article on sleeping pills (8 August, p. 296) with an exhortation to every doctor to undertake a searching review of his prescribing of hypnotic drugs. Many patients admitted to hospital are given hypnotics for a variety of understandable reasons. Unfortunately these drugs are sometimes continued unnecessarily after discharge, and once at home it may be more difficult for the patient to accept the few disturbed nights of sleep which may accompany cessation of the drug.

Insomnia is a characteristic feature of depressive illness, but one can assume that when treatment is effective the insomnia will cease and hypnotics can be discontinued. We report briefly an assessment of the sleep characteristics of three groups of patients for the ten days after a course of electroconvulsive therapy. Thirty patients were randomly assigned to one of three groups, receiving either sodium amylobarbitone, $200 \mathrm{mg}$., a placebo tablet, or no hypnotic medication. Two patients were withdrawn from the trial because of relapse Patients continued on any daytime antidepressive medication. The night nurse recorded hours slept and the quality of sleep-sound, restless, or disturbed and awake.

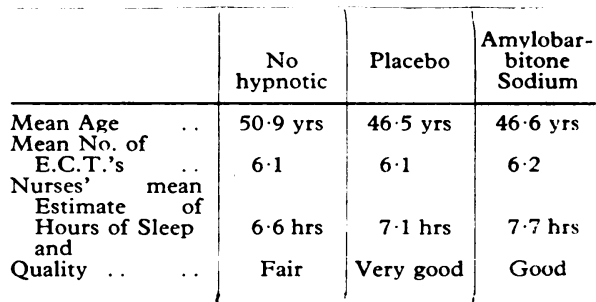

It is apparent that on average patients sleep reasonably well without any hypnotic better with a placebo, and best with a hypnotic and differences are small. In view of the risk of dependence, clearly it is important that hypnotics given to patients in hospital should be discontinued at the first opportunity, and before discharge. The few nights of disturbed sleep following withdrawal would then be experienced during the period of convalescence in hospital Instances where withdrawal is distressing may be helped by the use of a placebo.We are, etc.,

M. R. BOND. I. B. Pearson.

C. P. SEAGER.

Department of Psychiatry,
University of Sheffield, Yorks. 